Original Research Paper

\title{
An Extended Version of the Fuzzy-Euclidean Intelligent Fitness Model (FEIFM) Implementation for Selecting Personal Vehicle
}

\author{
Calvin Chang, Edwin and Ditdit Nugeraha Utama \\ Department of Computer Science, BINUS Graduate Program-Master of Computer Science, \\ Bina Nusantara University, Jakarta, Indonesia 11480
}

\author{
Article history \\ Received: 26-02-2019 \\ Revised: 17-05-2019 \\ Accepted: 09-08-2019 \\ Corresponding Author: \\ Calvin Chang \\ Department of Computer \\ Science, BINUS Graduate \\ Program-Master of Computer \\ Science, University Bina \\ Nusantara, Jakarta, Indonesia \\ 11480 \\ Email: calvin.chang@binus.ac.id
}

\begin{abstract}
Indeed, intelligent model is a sub-domain in computer science that its purposes utilized in numerous pieces of reality. Particularly in case of automotive industry, to select the most appropriate personal vehicle is challenging for the customers. The challenge was taken as a main problem of this study. In this research, the reasonableness is characterized by the customer parameters which portray the customer's identity. By utilizing the mix technique for fuzzy-logic and Euclidean distance calculation, the customer's identities are fitted into the personal-vehicle parameters. At long last, the constructed model for choosing personal vehicle plays several customer's parameters; e.g., age, gender, education, income and job. The model designed thru utilizing the object-oriented methodology. The result of simulation of 66 purchasers and 44 conceivable vehicles are able to propose the most reasonable vehicle for every purchaser. As an extended version, the model successfully delivers the completed scheme due to added parameters and method. It is a truthful contribution provided by this research.
\end{abstract}

Keywords: Fitness Model, Fuzzy Logic, Euclidean Distance, Personal Vehicle Selection

\section{Introduction}

Automotive industry is one of the biggest assembling part industries around the world (Liu et al., 2015). It is one of a few profoundly focused buyer industries (Caridade et al., 2017; Stoycheva et al., 2018). Also, it is an industry where the quantity of firms is intermediately low and item stages are utilized widely (Moreno and Terwiesch, 2013). The main thrust of its development is the utilization of individual autos like private vehicle use; with numerous points of interest to the private vehicle (e.g., accommodation, adaptability and security), it practically affects a fast development in private vehicle use, especially in urban territories (Nguyen-Phuoc et al., 2018).

Different reasons forever make the car business is heavily requested (Inayatulloh et al., 2018). The industry must be able to fulfill the government regulations and meet the society area requirements. The members as well observe and maintain a competitive edge in a rapidly changing business environment that is characterized by fluctuating customer demands, new legislations and stiff competitors (Schöggl et al., 2017).

People face wide and assorted choice circumstances. It is important to achieve basic decision making forms that generally include numerous clashing criteria and inspire the improvement of various Multi Criteria Decision Analysis (MCDA) techniques (Celik et al., 2015) applied to decision making problems and cases in the real world. This study was encouraged by multiple and conflicting criteria of the importance of the automotive industry. The different and clashing criteria of the significance of the car business energizes this investigation directly. It is in regards to the shrewd wellness demonstrating for supporting the purchasers of car industry in choosing the individual vehicle dependent on their identity (individual attributes) (Inayatulloh et al., 2018).

The main characteristics of a Multi Criteria Decision Making (MCDM) method include: (1) the choices to be assessed, (2) the criteria against which the choices are assessed, (3) scores that mirror the estimation of an option's normal act on the criteria and (4) criteria loads that measure the overall significance of every rule as contrasted and others (Amaral and Costa, 2014). This paper discusses the benefit of using a decision analytic tool referred to as MCDA to adjust the risks and advantages of choosing the individual vehicle. The combination between two methods implementations (i.e., fuzzy-logic conception and Euclidean distance calculation methods) that specifically implemented in case of individual vehicle selection is a strong novelty proposed by this study. 


\section{Theoretical View}

Intelligent model should be a set of technical ways combined by informational process and interacting with one person (or group of people) or working independently, that is able to make a decision strongly based on information, knowledge and incentive to produce an objective and find a rational way to achieve the goal (Pupkov, 2017). For example, Cooperative Intelligent Transport System (C-ITS) is a promising technology/conception which aims to practically enhance road safety, upgrade traffic management and increase driver comfort (Javed et al., 2019). This model uses data collection that contains all observable information of consumer parameters related to vehicle parameters for further analysis of the current vehicle type choice.

\section{Related Works}

The area of research studies talking the issue "decision making" is various and large. The various categories of decision making styles have been identified (Abubakar et al., 2019). MCDM is a type of universal operation research model widely used to solve the various decision-making problems where multiple criteria and alternatives exist. Life-Cycle Analysis (LCA) and MCDA methods were operated to classify vehicles on the basis of their impact on the environment (Domingues et al., 2015). Recently, the study combined of life-cycle maintainability appraisal and multi-criteria based leadership structure to distinguish the ideal U.S. traveler vehicle armada, by looking at seven vehicle types as far as sixteen manageability impacts, was successfully performed (Onat et al., 2016). Several researchers connected MCDA techniques with regards to electric vehicle appropriation (Fazeli et al., 2017).

A crossover multi-criteria leadership strategy has been created by joining diagram hypothesis and systematic chain of importance procedure to rank the elective fills for transportation. A crossover multicriteria leadership technique by consolidating chart hypothesis and systematic chain of importance procedure to rank the elective powers for transportation was conducted (Lanjewar et al., 2015). In this research, MADM and MODM spoke to two principle classifications of MCDM strategies. In these models, the essential objectives were to choose the best option or gathering of choices for a predefined inclination set dependent on the accessible choices' exhibitions as for numerous criteria (Onat et al., 2016).

The intuitive Decision Support System (DSS) proposes the perfect procedure that coordinates monetary assessment, advertise dissemination and government directions (Al-Alawi and Coker, 2018). DSS is used for different purposes like providing decision support for process control, process quality control, material and proses selection (Karmarkar and Gilke, 2018). In real life, many processes of human activity are closer to fuzzy processes rather than mathematically procedures. Furthermore, the quantification of explanatory power of mobility-related attributes in clarifying vehicle proprietorship choice was performed deliberately (Inayatulloh et al., 2018). The study result featured the nature of movement impacts the responsibility for method of transport (Utama et al., 2016). Besides, the connection between consumer's travel attitude, personality, lifestyle, age, gender, job, education, income and vehicle count factors with the people's vehicle type decision was demonstrated sign. Those variables and created aggregate decision display were effectively characterized (Choo and Mokhtarian, 2004)

\section{Research Methodology}

This paper utilized the object-oriented analysis and configuration stage. A model of the framework paying little heed to imperatives (e.g., fitting innovation) was made. This was normally done through specific tools like use case and class diagrams of the essential items utilizing theoretical model. Object-oriented research (Mathiassen et al., 2000) illustrates and clarifies the design of the association between actors and models and the interconnection between entities. The interaction can be likewise between segments of a system or between a system and different system.

The technique fuzzy logic (Zadeh, 2008) is utilized to pick suitable rules for tracing the real fuzzy value of parameters or keeping away from deterrents as indicated by the circumstance. The fuzzy logic has high opportunity to influence the calculated model to be able to receive human linguistic factors. The fuzzy logic technique gives an implication that contains all change of linguistic control procedure depending on master learning into a programmed control system. The procedure of change called fuzzificationdefuzzification and it realizes the output.

This fuzzification involves a domain transformation where crisp inputs measured and passed into the engine for processing before transformed into fuzzy outputs. Defuzzification process is hard to produce a quantifiable result in crisp logic, given fuzzy sets and corresponding membership degrees. It is operated to change the crisp input to crisp output ready to be operated into the model.

Finally, the Euclidean distance calculation method (Utama et al., 2017) is technically exploited for corresponding between consumer's personalities and vehicle parameters. The result is a distance that calculated between two nodes or among several nodes. In this study, the distance can be used to find the similarity of one parameter with other parameters and the result analogically describes a gap value between the consumer's personalities with vehicle.

The value (Utama et al., 2016) is comparison 
between distance values of two parameters with maximum distance. The mathematical equation formula used to calculate the Euclidean distance is delivered in Equation (1); with $p n$ is the $n$th parameter, $c n$ represents the $n$th consumer parameter and $v n$ symbolizes the $n t h$ vehicle parameter. After that, the results collected relative value of distance from Equation (1) is figured through Equation (2). The objective capacity of the model purposes itself is estimated by utilizing the Equation (3):

$$
\begin{aligned}
& E D R_{p n}=\frac{\left(P_{c n}-P_{v n}\right)^{2}}{\max \left(\left(P_{c n}-P_{v n}\right)^{2}\right)} \\
& E D R=\sqrt{\sum_{i=1}^{n}\left(E D R_{p n}\right)} \\
& \min f(c, v, n)=\sqrt{\sum_{i=1}^{n}\left(\frac{\left(P_{c n}-P_{v n}\right)^{2}}{\max \left(\left(P_{c n}-P_{v n}\right)^{2}\right)}\right)}
\end{aligned}
$$

This research is using fuzzy distance triangular membership function (Fig. 1) to elaborate the process of fuzzy logic conception. If the distance value is between 0.0 and 0.2 , then the similarity among parameters is indicated with high (the opposite of distance parameter). When distance value is between 0.2 until 0.8 , then the similarity between parameters is still medium. If distance value between 0.8 and 1.0, then the parameter has low similarity oppositely. This study is also using a gap to categorize the distance value output and give the limitation for each category in fuzzy distance. There are four gap and each gap has the limitation itself.

If the gap equals 1 (Fig. 2), then ordinal value input is 0.0 or 0.2 and uses Equation (4). If (high value) then (low value) $=0.9$ and the maximum distance between two parameters will be 0.9 . The example is job parameter that could be full time or part time parameters. Then the maximum distance between parameter is 0.9.

Figure 3 uses Equations (4) and (5) and requires 3 parameters and the distance between one another is 0.1 and 0.9. The Equations (4), (5) and (6) used in Fig. 4 and it requires 4 parameters. The distance output for one parameter with the others is $0.1,0.5$ and 0.9 . Equations (7) and (8) are used to define the Equations (9) and (10). Figure 5 uses Equations (4), (5), (9) and (10) and the distance outputs for one parameter with the others are $0.1,0.4,0.6$ and 0.9 :

$$
\begin{aligned}
& \operatorname{IF}(H) \operatorname{then}(L)=\frac{1 \times 0.8+1 \times 1}{1+1}=0.9 \\
& I F(L) \operatorname{then}(H)=\frac{1 \times 0+1 \times 0.2}{1+1}=0.1
\end{aligned}
$$

$$
\begin{aligned}
& \operatorname{IF}(M) \text { then }(M)=\frac{1 \times 0.5}{1}=0.5 \\
& \text { Trapezoidal Area } 1=\frac{(0.5+(1-0.33) \times 0.5)) \times 0.33}{2}=0.1378
\end{aligned}
$$

Trapezoidal Area $2=\frac{(0.6+(1-0.67) \times 0.6)) \times 0.67}{2}=0.2673$

$\operatorname{IF}(L)$ then $(M)=\frac{0.1378 \times 0,2+0.2673 \times 0.5}{0.1378+0.2673}=0.4$

$\operatorname{IF}(M) \operatorname{then}(H)=\frac{0.2673 \times 0.5+0.1378 \times 0.8}{0.2673+0.1378}=0.6$

\section{Results}

The distance between vehicle and customer is distance summation for each related parameter. It specifies technically the right customer selects the appropriate vehicle. The distance value of one customer for every vehicle parameter must be unique (the least distance value show the highest similarity). The direct (D) distance type representing every consumer parameter definitely has the same attribute with the vehicle parameters. The condition (C) distance type must use the original and real research data. The result value in (C) must be proven and guaranteed by the researchers in this area.

Table 1 shows the mapping of consumer and vehicle parameters with the distance value type. The study of (Choo and Mokhtarian, 2004), in this research, was analyzed, synthesized used to determine the distance value of vehicleType parameter. The Euclidean distance value of the value of the vehicleType parameter (small, mid-size, large, compact, minivan, SUV, sport and pickup) is determined by the personal characteristics of the consumer (life style, personality, distance travel, age, gender, education, income, job and vehicle). The result of parameters mapping is displayed in Table 2 .

Based on Table 1, five of seven parameters are designed via fuzzy logic method. All parameters have been inputted by customer was changed into the new car parameter filled. Then it easily categorizes what type of vehicle is going to fit with the customer. All consumer and vehicle parameters are described by class diagram; where all attributes are determined undoubtedly in the conceptual model in Fig. 6.

The added parameters in this extended model are age, gender, education, income, job and vehicle number. Based on the class diagram (Fig. 6), the parameter customer DOB is used to know the age of the customer. The parameter last Education is used to find the customer's last education level that will be in higher education or lower education value. Here, we concluded that consumers that last education is college, university 
or higher include in higher education and lower education is high school or lower. Furthermore, the parameter monthly Income is used to classify the income of customer into three range (i.e., lower, middle higher). The parameter working Hours is operated to classify the job of customer into part-time or full-time. And, lastly parameter vehicle Amount is functioned to count the customers total vehicle.

The output of Fig. 1 is three common types of distance value (i.e., high, medium and low values). Figure 2 describes when the maximum ordinal gap value is equal to 1; the output will be 0.0 for the optimum value and 0.9 for the lowest value. Figure 3 is operated when maximum ordinal gap value equals 2 ; where the outputs are 0.0 for the optimum value, 0.1 for intermediate value 0.9 for the lowest value. Moreover, Fig. 4 illustrates the condition when maximum ordinal gap value is equal to 3 ; where the outputs are going to be 0.0 for the optimum value, 0.1 for the optimum intermediate value, 0.5 for the least intermediate value 0.9 for the lowest value. Thus, Fig. 5 is benefited when maximum ordinal gap value equals 4; where the output will be 0.0 for the optimum value, 0.1 for the optimum intermediate value, 0.4 is the intermediate value, 0.6 is the least intermediate value 0.9 for the lowest value.

Three common types of distance value have been implemented and depend on the gap; 0.0 for the optimum value of distance, 0.5 for intermediate value 0.9 for the lowest value. Three common distance values have been implemented and depend on the gap; 0.0 for the optimum distance value, 0.5 for the intermediate value and 0.9 for the lowest value. If the parameter value of the consumer characteristic fits the vehicle type and has a very good relationship, the value can be 0.0 (the minimum value). Otherwise, the distance value is 0.9 (the maximum value of the calculation) then the relationship is bad. For the other vehicle type, the value 0.5 (intermediate calculation value) is used.

The developed model is practically able to display a suggestion about vehicle that has best fit-value and near with consumer parameter compared with the other vehicles. The example of Euclidean distance value determination using IF-Else Statement can be seen in Code 1:

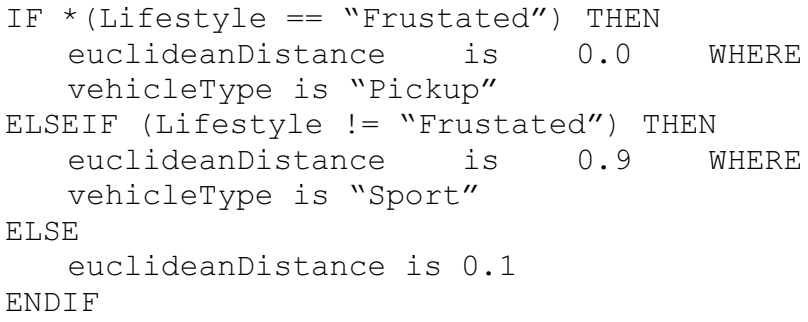

Code 1: The statement code for determining vehicle type on consumer's frustrated lifestyle characteristics

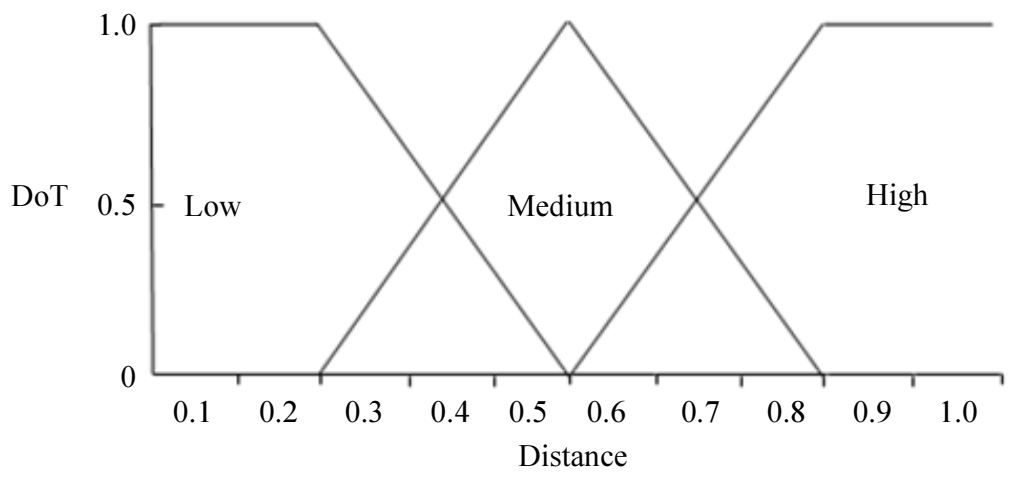

Fig. 1: Fuzzy triangular membership function for distance parameter

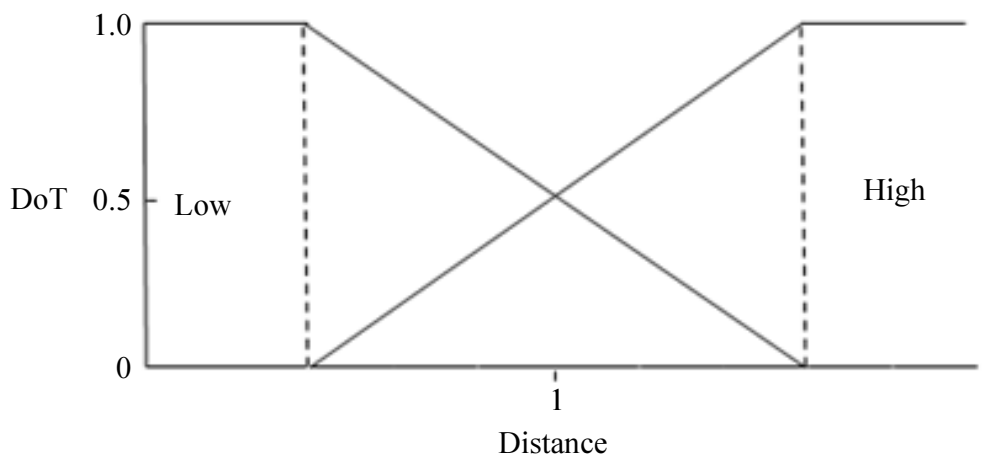

Fig. 2: Fuzzy triangular membership function for maximum ordinal of gap value equals 1 


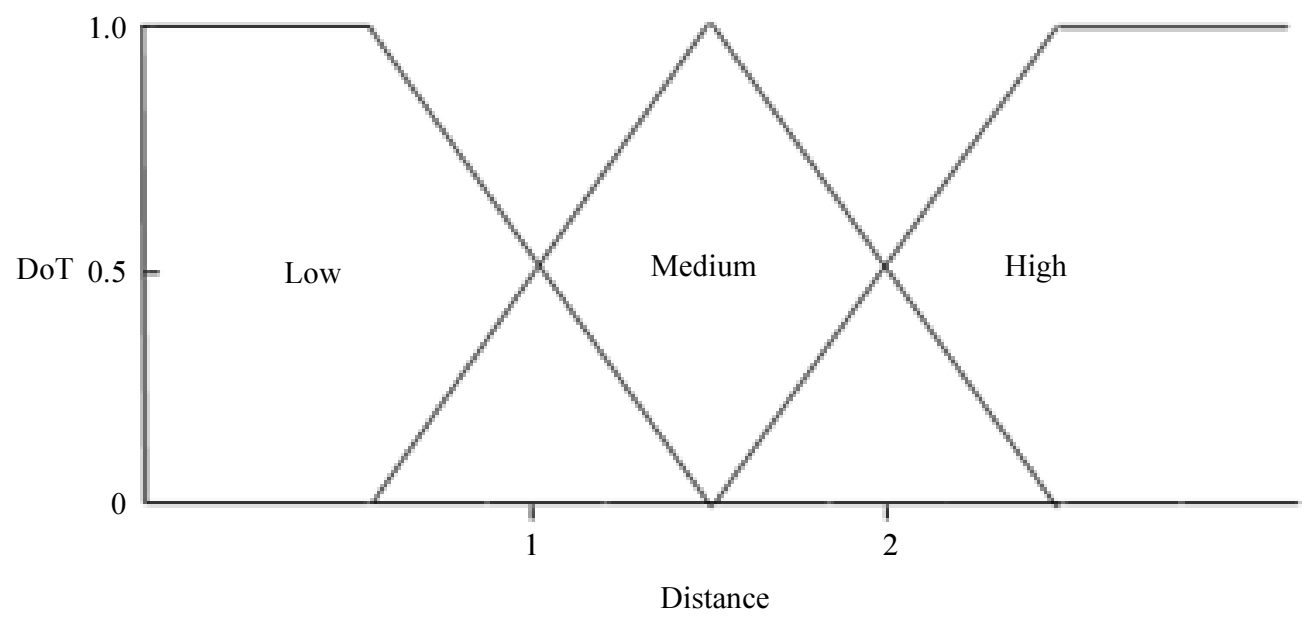

Fig. 3: Fuzzy triangular membership function for maximum ordinal value of gap equals 2

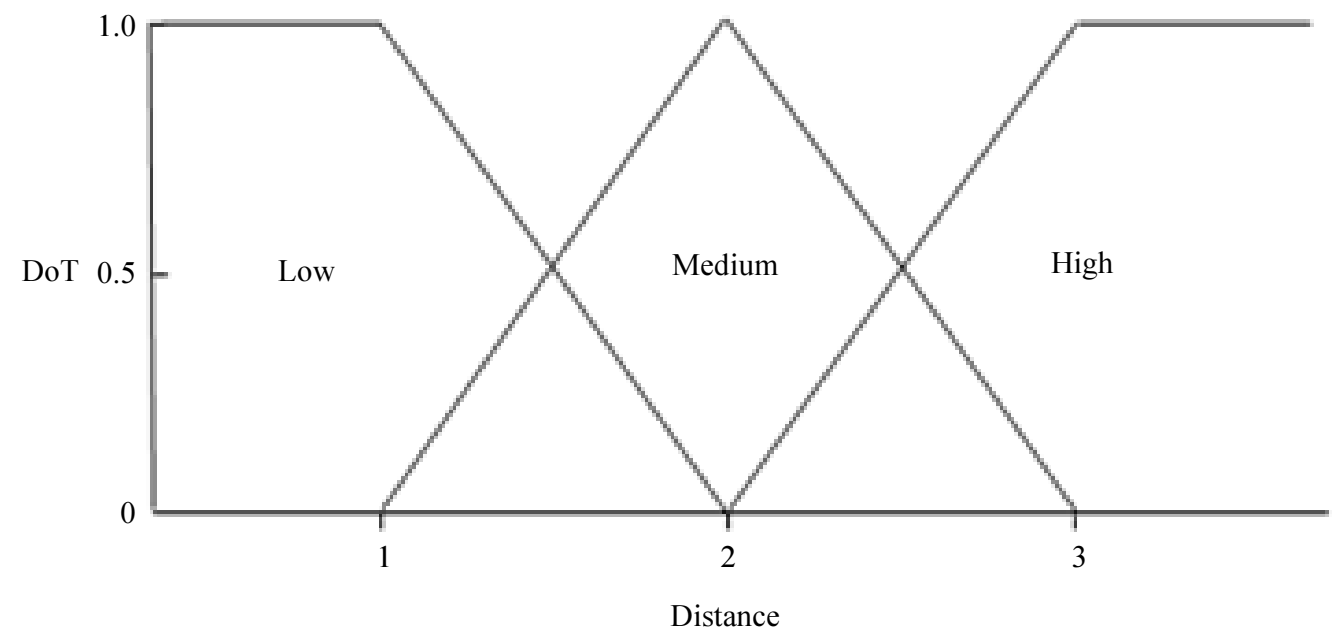

Fig. 4: Fuzzy triangular membership function for maximum ordinal value of gap equals 3

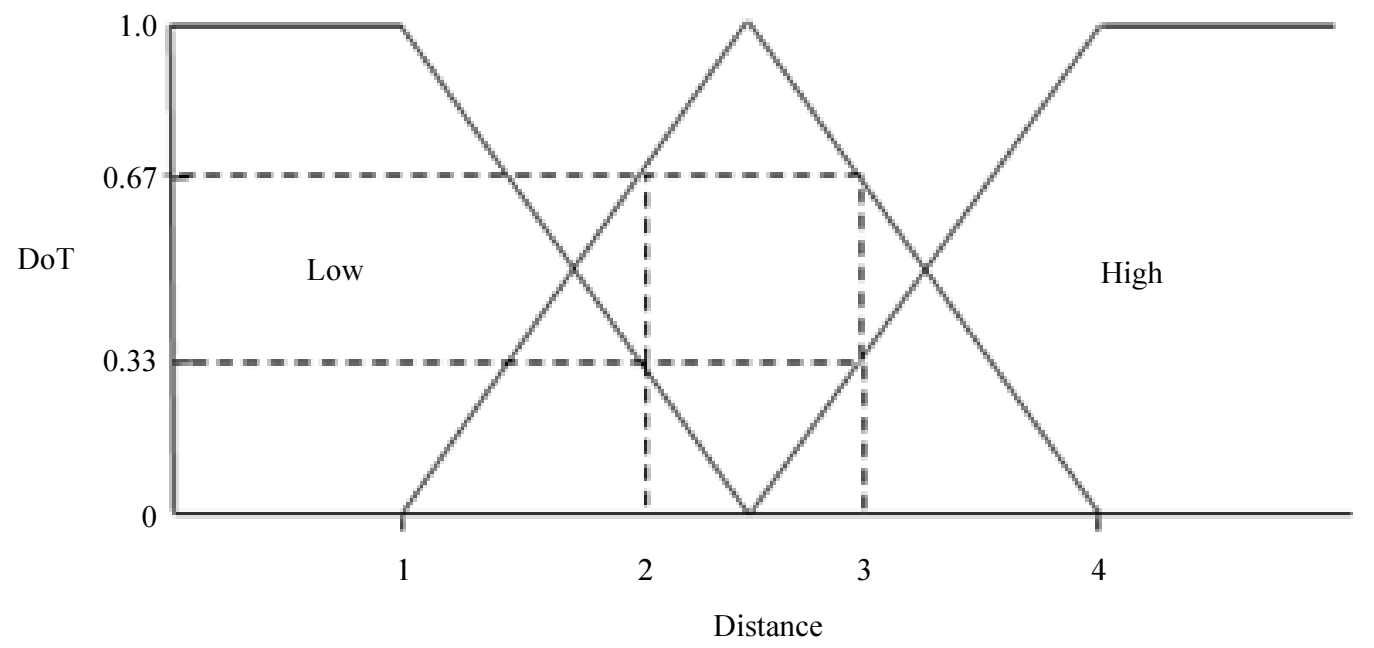

Fig. 5: Fuzzy triangular membership function for maximum ordinal value of gap equals 4 


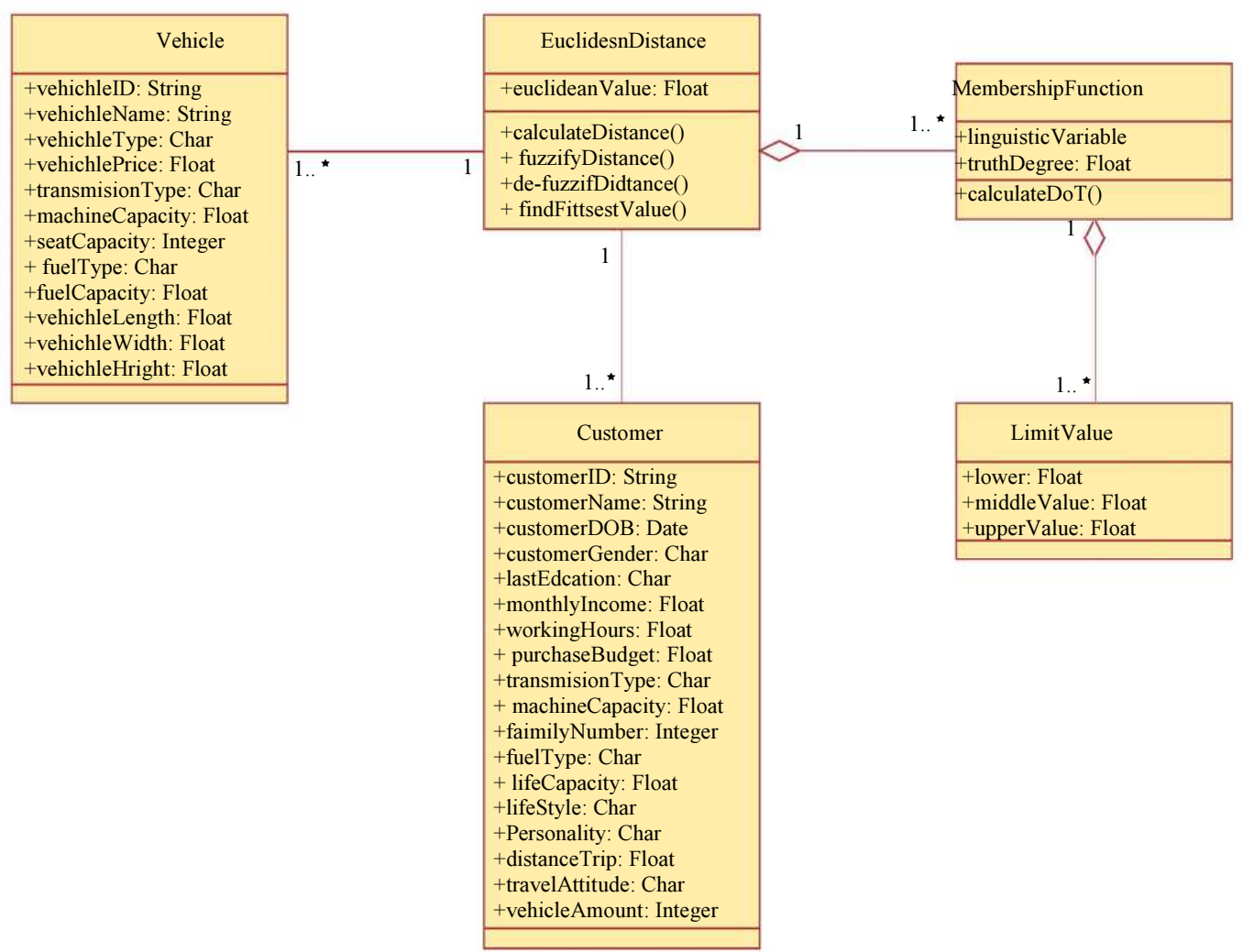

Fig. 6: Class diagram for constructed model

Table 1: Consumer-vehicle related parameter

\begin{tabular}{llll}
\hline No & Consumer parameter & Vehicle parameter & Distance type \\
\hline 1 & purchaseBudget & vehiclePrice & Direct \\
2 & familyNumber & seatCapacity & Direct \\
3 & fuelType & fuelType & Direct \\
4 & transmissionType & transmissionType & Direct \\
5 & fuelCapacity & fuelCapacity & Direct \\
6 & machineCapacity & machineCapacity & Direct \\
7 & Lifestyle, Personality, Distance Trip, Travel Attitude, & vehicleType & Condition \\
& Age, Gender, Education, Income, Job, Vehicle & & \\
\hline
\end{tabular}

Table 2: Vehicle type based on consumer characteristics

\begin{tabular}{llll}
\hline No. & Consumer parameter & Parameter value & Vehicle type \\
\hline 1 & Lifestyle & Frustrated & MORE LIKELY for Pickup \\
& & LESS LIKELY for Sport or SUV \\
& Family community & MORE LIKELY for Large \\
& oriented Workaholic & LESS LIKELY for Small \\
& & MORE LIKELY for Luxury or \\
& & Pickup LESS LIKELY for Small \\
& Status Seeking & MORE LIKELY for Luxury or \\
& & Sports LESS LIKELY for Small \\
& Adventure Seeker & MORE LIKELY for Sports or \\
& & SUV LESS LIKELY for Pickup \\
& Organizer & MORE LIKELY, for SUV or Mid Size \\
& & LESS LIKELY for Sports \\
& Loner & MORE LIKELY for Small or \\
& & Sport LESS LIKELY for Large \\
& Calm & MORE LIKELY for Minivan or \\
& & Compact LESS LIKELY for Sport
\end{tabular}


Table 2: Continue

\begin{tabular}{|c|c|c|c|}
\hline \multirow[t]{3}{*}{3} & Distance Trip & Short Distance Trip & MORE LIKELY for SUV \\
\hline & & Lono Distance Trin & LESS LIKELY for Pickup \\
\hline & & Long Distant THP & LESS LIKELY for Compact \\
\hline \multirow[t]{10}{*}{4} & Travel Attitude & Travel Dislike & MORE LIKELY for Luxury or Large \\
\hline & & & LESS LIKELY for Sport \\
\hline & & Pro Environmental Solution & MORE LIKELY for Luxury \\
\hline & & & LESS LIKELY for Large \\
\hline & & Commute Benefit & $\begin{array}{l}\text { MORE LIKELY for Minivan or Large } \\
\text { LESS LIKELY for Compact }\end{array}$ \\
\hline & & Travel Freedom & MORE LIKELY for Luxury or SUV \\
\hline & & & LESS LIKELY for Compact \\
\hline & & Travel Stress & $\begin{array}{l}\text { MORE LIKELY for Small or Compact } \\
\text { LESS LIKELY for Luxury }\end{array}$ \\
\hline & & Pro High Density & MORE LIKELY for Small or \\
\hline & & & Sport LESS LIKELY for Large \\
\hline \multirow[t]{4}{*}{5} & Age & $17-29$ & MORE LIKELY for Sports \\
\hline & & $30-40$ & MORE LIKELY for Small or SUV \\
\hline & & $41-60$ & MORE LIKELY for Minivan or Pickup \\
\hline & & $61<$ & MORE LIKELY for Large or Luxury \\
\hline \multirow[t]{2}{*}{6} & Gender & Male & MORE LIKELY for Large or Luxury \\
\hline & & Female & $\begin{array}{l}\text { MORE LIKELY for Small or } \\
\text { Mid-Sized or Minivan }\end{array}$ \\
\hline \multirow[t]{2}{*}{7} & Education & Highly Educated & $\begin{array}{l}\text { MORE LIKELY for Small or } \\
\text { Luxury or Sports or SUV }\end{array}$ \\
\hline & & Less Educated & MORE LIKELY for Large or Pickup \\
\hline \multirow[t]{4}{*}{8} & Income & High & $\begin{array}{l}\text { MORE LIKELY for Mid-Sized or } \\
\text { Luxury or SUV }\end{array}$ \\
\hline & & Middle & MORE LIKELY for Pickup or Compact \\
\hline & & Lower & MORE LIKELY for Small or \\
\hline & & & Large or Sports or Minivan \\
\hline \multirow[t]{2}{*}{9} & Job & Full Time & MORE LIKELY for Small or Compact or SUV \\
\hline & & Part Time & MORE LIKELY for Large or Mid-Sized \\
\hline \multirow[t]{4}{*}{10} & Vehicle & Single & MORE LIKELY for Small or Compact \\
\hline & & Two & MORE LIKELY for Pickup \\
\hline & & Multi & MORE LIKELY for Large or \\
\hline & & & Luxury or Minivan \\
\hline
\end{tabular}

In the report page (Fig. 7) of the recommended personal vehicle for more than 50 customers and 44 personal vehicle types, the simulation results are finally exposed. The model can provide the specified customer with the best personal vehicle. Figure 8 presents an example of a customer's fitness calculation. The graph assesses the model's accuracy in relation to the proposed decision.

\section{Discussion}

This study is an extended version of (Inayatulloh et al., 2018). Inayatulloh et al. (2018) developed a model that suggests the consumers to select a suitable vehicle based on their characteristics. We adopted the key idea of their constructed model and all common parameters. Nonetheless, we considered consumer age, gender, education, income vehicle number as other imperative parameters in developing the extended model. Afterward, the vehicle attributes that depend on the consumer's parameters were combined. To build up the model, fuzzy logic and Euclidean distance calculation were deliberately intermixed.
All parameters in the result of study (Choo and Mokhtarian, 2004) were analyzed and then utilized in the developed model; they are joined parameters among lifestyle, personality, distance trip, travel attitude, age, gender, education, income, job and vehicle number. Now, many methods of MCDA and LCA have been used and implemented in real world. The results is visible and accessed in research papers. The constructed model in this study explains how consumer get a recommendation personal vehicle based on the distance selection between vehicle parameters link to consumer parameters.

The study of (Inayatulloh et al., 2018) used fuzzy triangular method, however it was not defined well. Also, the gap is unknown slightly. Our paper has defined the triangular method with the maximum gap value from one until four. The output value has been categorized into the best, intermediate lowest values. From the study of (Choo and Mokhtarian, 2004), frustrated people is less likely to buy the sport and luxury car. We have changed the vehicle type value in frustrated parameter based on consumer characteristics. We added already six more consumer parameters exclude lifestyle, personality, distance trip travel attitude of (Inayatulloh et al., 2018). 


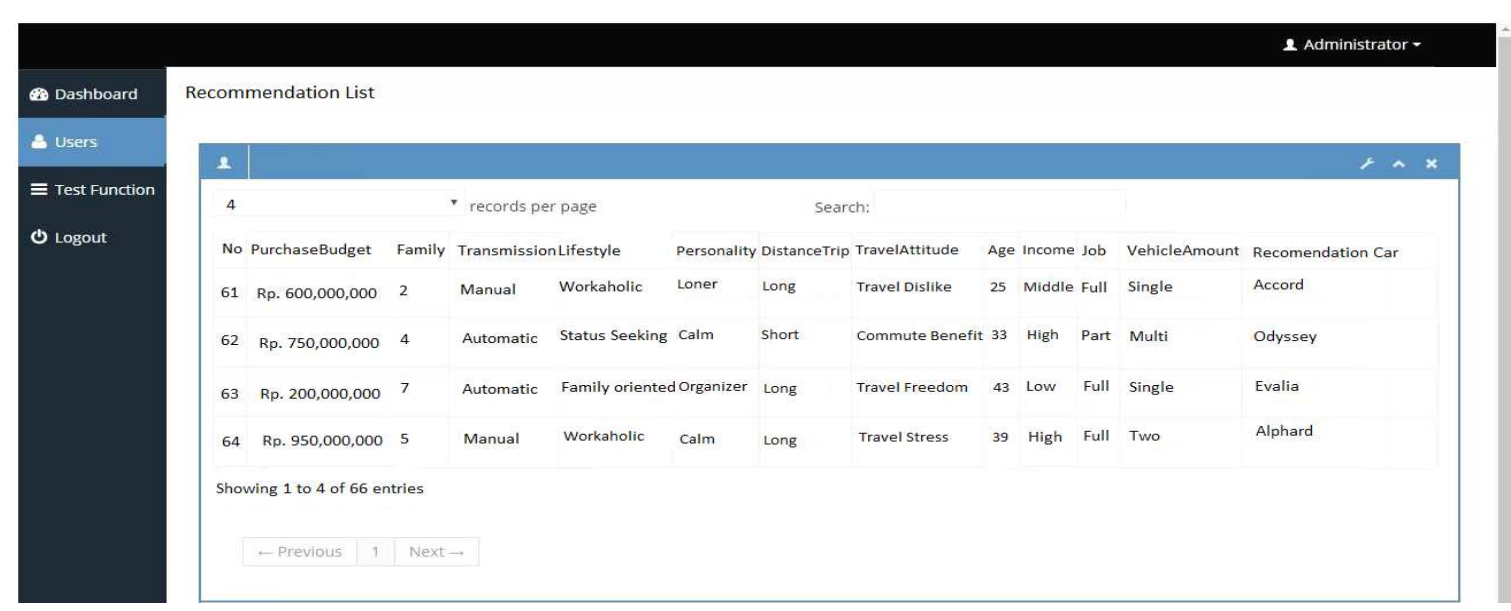

Fig. 7: Report page of constructed model

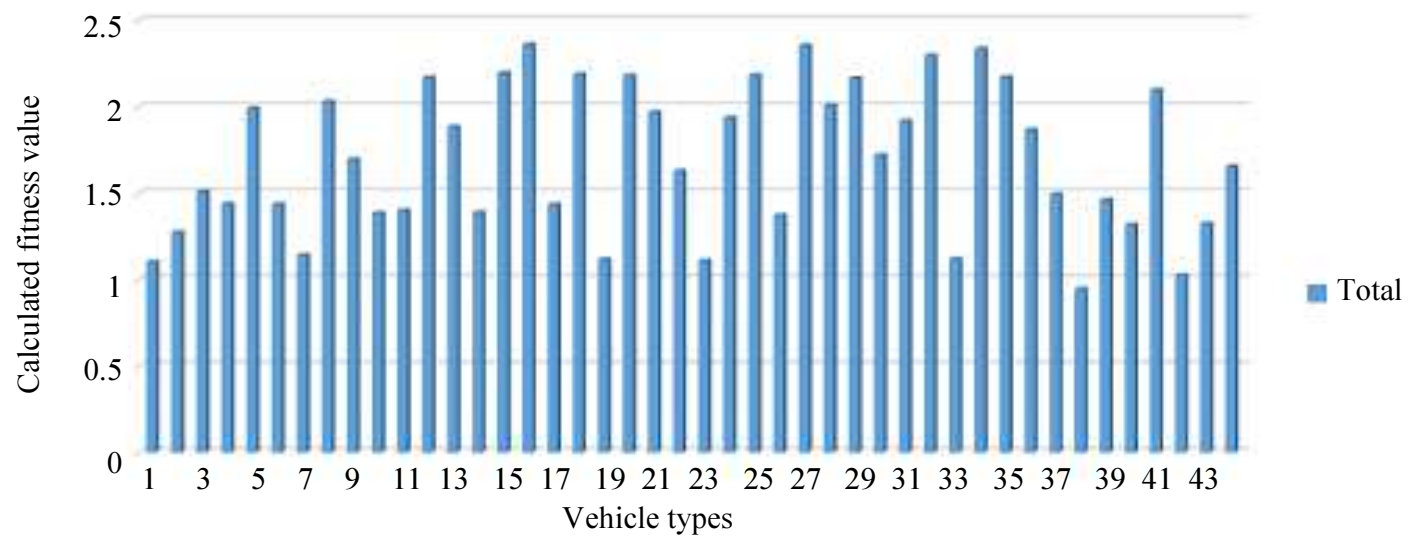

Fig. 8: The report results of fitness value determination for a customer

\section{Conclusion and Further Works}

The Fuzzy-Euclidean intelligent fitness model has been developed academically. The model is able to recommend the consumers to select the most suitable vehicle based on their characteristics. The model is extended version of (Inayatulloh et al., 2018). The model adopted two types of main method; they are fuzzy logic to declare the fuzzy value of parameters and Euclidean distance calculation to determine the fitness value.

The proposed mechanism makes conceivably the model can use human linguistic variable and Euclidean distance calculation that functioned practically to ascertain the closeness consumer's identity parameter and vehicle parameters. The client trademark is demonstrated to be fitted with vehicle traits. Here, ten individual purchaser parameters are coordinated with ten sorts of vehicle qualities. By utilizing the mix technique, the model selects the suitable vehicle suggestion for every client who has delivered their personality and their vehicle characteristics.
Other parameters are possibly abled to be studied to extend the model. Environmental effects, emission number, consumer's vacancy many more; are the example of such parameters. Also, optimization method can be implemented into this model to find the best optimal value of fitness; like water flow algorithm, ant colony optimization, simulated-annealing, etc.

\section{Acknowledgment}

We would like to thank Bina Nusantara University who has supported and sponsored our studies and works, particularly Bina Nusantara Graduate Program, Master of Computer Science.

\section{Author's Contributions}

Calvin Chang: Contributed to the data synchronizing, computer model developing and testing, manuscript drafting and also manuscript finalizing.

Edwin: Contributed to the data synchronizing, computer model developing and testing, manuscript 
drafting and also manuscript finalizing.

Ditdit Nugeraha Utama: Contributed to the whole process supervising for data synchronizing, computer model constructing, manuscript writing and also directly encompassed in manuscript finalizing.

\section{Ethics}

This manuscript substance is the authors' own original work and has not been previously published somewhere else. Authors already read and approved the manuscript and no potential ethical issues immersed.

\section{References}

Abubakar, A.M., H. Elrehail, M.A. Alatailat and A. Elçi, 2019. Knowledge management, decisionmaking style and organizational performance. J. Innovat. Knowledge, 4: 104-114.

DOI: $10.1016 /$ j.jik.2017.07.003

Al-Alawi, B.M. and A.D. Coker, 2018. Multi-criteria decision support system with negotiation process for vehicle technology selection. Energy, 157: 278-296. DOI: 10.1016/J.ENERGY.2018.05.142

Amaral, T.M. and A.P.C. Costa, 2014. Improving decision-making and management of hospital resources: An application of the PROMETHEE II method in an emergency department. Operat. Res. Health Care, 3: 1-6. DOI: $10.1016 / J . O R H C .2013 .10 .002$

Caridade, R., T. Pereira, F. L. Pinto and F.J.G. Silva, 2017. Analysis and optimisation of a logistic warehouse in the automotive industry. Procedia Manufactur., 13: 1096-1103. DOI: 10.1016/J.PROMFG.2017.09.170

Celik, E., M. Gul, N. Aydin, A.T. Gumus and A.F. Guneri, 2015. A comprehensive review of multi criteria decision making approaches based on interval type-2 fuzzy sets. Know. Based Syst., 85: 329-341. DOI: 0.1016/J.KNOSYS.2015.06.004

Choo, S. and P.L. Mokhtarian, 2004. What type of vehicle do people drive? The role of attitude and lifestyle in influencing vehicle type choice. Transportat. Res. Part A: Policy Practice, 38: 201-222.

DOI: 10.1016/J.TRA.2003.10.005

Domingues, A.R., P. Marques, R. Garcia, F. Freire and L.C. Dias, 2015. Applying multi-criteria decision analysis to the life-cycle assessment of vehicles. J. Cleaner Product., 107: 749-759.

DOI: 10.1016/J.JCLEPRO.2015.05.086

Fazeli, R., B. Davidsdottir, E. Shafiei, H. Stefansson and E.I. Asgeirsson, 2017. Multi-criteria decision analysis of fiscal policies promoting the adoption of electric vehicles. Energy Procedia, 142: 2511-2516. DOI: 10.1016/J.EGYPRO.2017.12.191
Inayatulloh, P., L. Fatia, F.N. Efendi, M.Y.F., Viandari and D.N. Utama, 2018. A Fuzzy-Euclidean Intelligent Fitness Model (FEIFM) implementation for selecting personal vehicle. Proceedings of the Indonesian Association for Pattern Recognition International Conference, Oct. 1-2, pp: 29-33. DOI: $10.1109 /$ INAPR.2018.8627021

Javed, M.A., S. Zeadally and E.B. Hamida, 2019. Data analytics for cooperative Intelligent Transport Syst. Vehicular Commu., 15: 63-72. DOI: 10.1016/J.VEHCOM.2018.10.004

Karmarkar, A.U. and N.R. Gilke, 2018. Fuzzy Logic based decision support systems in variant production. Mater. Today, 5: 3842-3850. DOI: 10.1016/J.MATPR.2017.11.638

Lanjewar, P.B., R.V. Rao and A.V. Kale, 2015. Assessment of alternative fuels for transportation using a hybrid graph theory and analytic hierarchy process method. Fuel, 154: 9-16. DOI: 10.1016/J.FUEL.2015.03.062

Liu, Y., Y. Liu and J. Chen, 2015. The impact of the Chinese automotive industry: Scenarios based on the national environmental goals. J. Cleaner Product., 96: 102-109. DOI: 10.1016/J.JCLEPRO.2014.05.015

Mathiassen, L., A. Munk-madsen, P. Axel and J. Stage, 2000. Object-oriented analysis and design michael Jackson writes.

Moreno, A. and C. Terwiesch, 2013. The effects of product line breadth: Evidence from the automotive industry. Ssrn.

Nguyen-Phuoc, D.Q., G. Currie, C. De Gruyter and W. Young, 2018. How do public transport users adjust their travel behaviour if public transport ceases? A qualitative study. Transportat. Res. Part F: Traffic Psychol. Behaviour, 54: 1-14. DOI: 10.1016/J.TRF.2018.01.009

Onat, N.C., M. Kucukvar, O. Tatari and Q.P. Zheng, 2016. Combined application of multi-criteria optimization and life-cycle sustainability assessment for optimal distribution of alternative passenger cars in U.S. J. Cleaner Product., 112: 291-307. DOI: 10.1016/J.JCLEPRO.2015.09.021

Pupkov, K.A., 2017. Intelligent systems: Development and Issues. Procedia Comput. Sci., 103: 581-583. DOI: 10.1016/J.PROCS.2017.01.069

Schöggl, J.P., R.J. Baumgartner and D. Hofer, 2017. Improving sustainability performance in early phases of product design: A checklist for sustainable product development tested in the automotive industry. J. Cleaner Product., 140: 1602-1617. DOI: 10.1016/J.JCLEPRO.2016.09.195 
Stoycheva, S., D. Marchese, C. Paul, S. Padoan and A. Juhmani et al., 2018. Multi-criteria decision analysis framework for sustainable manufacturing in automotive industry. J. Cleaner Product., 187: 257-272. DOI: 10.1016/J.JCLEPRO.2018.03.133

Utama, D.N., F. Fitroh, Y. Nuryasin, E. Rustamaji and I. Qoyim, 2017. D and T: An euclidean distance optimization based intelligent donation system model for solving the community's problem. J. Phys. Series, 8: 012005-012005.

DOI: $10.1088 / 1742-6596 / 801 / 1 / 012005$
Utama, D.N., S.M. Dedy, W.L. Ni'matun, P.M.A. Alam and P. Lestari, 2016. F-multicriteria based decision support system for road repair and maintenance (case study: Three areas in tangerang selatan, province Banten, Indonesia). Int. J. Manage. Applied Sci., 2: 1-5.

Zadeh, L.A., 2008. Is there a need for fuzzy logic?. Inform. Sci., 178: 2751-2779.

DOI: $10.1016 / J . I N S .2008 .02 .012$ 